\title{
FY20 Status report on the Molten Salt Thermodynamic Database (MSTDB) development
}

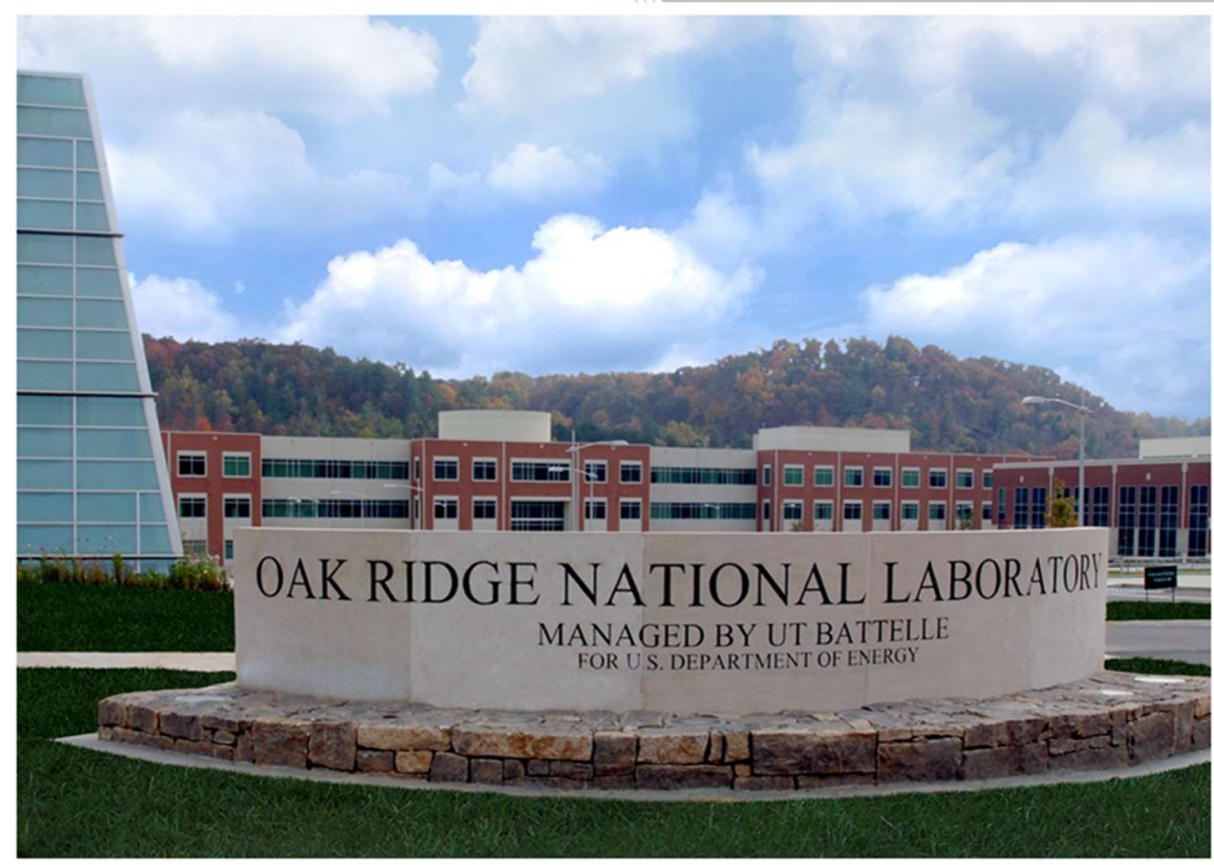

Approved for public release. Distribution is unlimited.
$\mathrm{J}$ Ard

K Johnson

M Christian

J Schorne-Pinto

$J$ Yingling

T Besmann

J McMurray

J Peng

September 30, 2020 


\section{DOCUMENT AVAILABILITY}

Reports produced after January 1, 1996, are generally available free via US Department of Energy (DOE) SciTech Connect.

Website www.osti.gov

Reports produced before January 1, 1996, may be purchased by members of the public from the following source:

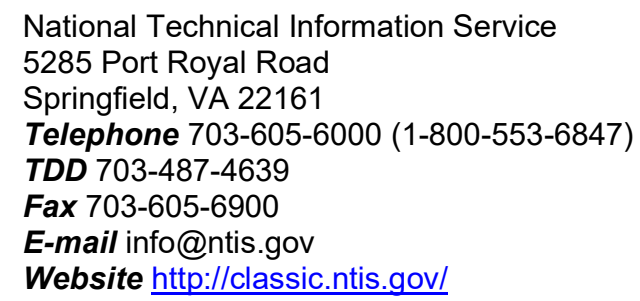

Reports are available to DOE employees, DOE contractors, Energy Technology Data Exchange representatives, and International Nuclear Information System representatives from the following source:

Office of Scientific and Technical Information

PO Box 62

Oak Ridge, TN 37831

Telephone 865-576-8401

Fax 865-576-5728

E-mail reports@osti.gov

Website http://www.osti.gov/contact.html

This report was prepared as an account of work sponsored by an agency of the United States Government. Neither the United States Government nor any agency thereof, nor any of their employees, makes any warranty, express or implied, or assumes any legal liability or responsibility for the accuracy, completeness, or usefulness of any information, apparatus, product, or process disclosed, or represents that its use would not infringe privately owned rights. Reference herein to any specific commercial product, process, or service by trade name, trademark, manufacturer, or otherwise, does not necessarily constitute or imply its endorsement, recommendation, or favoring by the United States Government or any agency thereof. The views and opinions of authors expressed herein do not necessarily state or reflect those of the United States Government or any agency thereof. 
Department of Energy Office of Nuclear Energy

Nuclear Energy Advanced Modeling and Simulation Program

FY20 Status report on the Molten Salt Thermodynamic Database (MSTDB) development

\author{
Author(s) \\ $\mathrm{J}$ Ard \\ K Johnson \\ M Christian \\ J Schorne-Pinto \\ J Yingling \\ T Besmann \\ J McMurray \\ J Peng
}

Date Published:

September 30, 2020

Prepared by

OAK RIDGE NATIONAL LABORATORY

Oak Ridge, TN 37831-6283

managed by

UT-BATTELLE, LLC

for the

US DEPARTMENT OF ENERGY

under contract DE-AC05-00OR22725 



\section{CONTENTS}

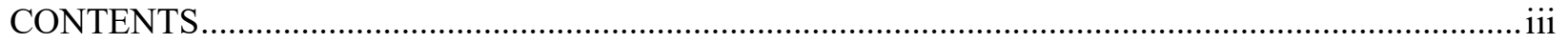

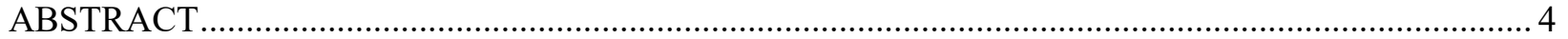

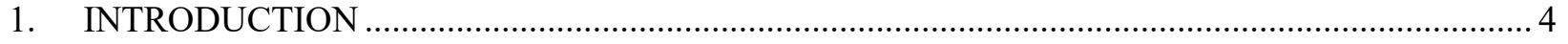

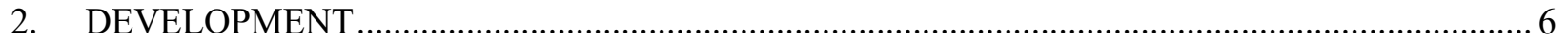

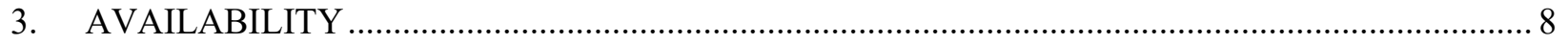

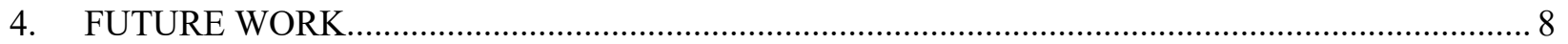

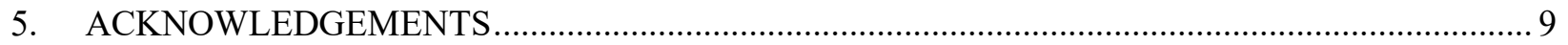

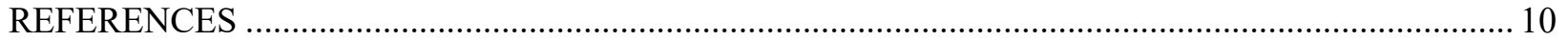

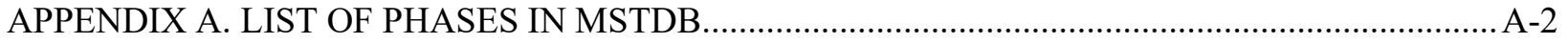




\begin{abstract}
The current status of the Molten Salt Thermodynamic Database (MSTDB) is reported. While a series of informational exchange meetings with Moten Salt Reactor (MSR) developers has given the NEAMS program insight into the systems of interest, the current effort is devoted to mining data already available in the literature for continued development of MSTDB. Many relevant systems have not been previously studied. Therefore, once the data from the literature is completely reviewed, curated, and used as inputs for MSTDB, new thermodynamic values will need to be generated using computational and experimental approaches.
\end{abstract}

\title{
1. INTRODUCTION
}

The Molten Salt Thermodynamic Database $(M S T D B)$ consists of Gibbs energy models for fluoride and chloridebased systems of interest for molten salt reactor (MSR) technology and related heat transfer applications. It has been prepared for its initial public release through the code.ornl GitLab repository hosted by Oak Ridge National Laboratory (ORNL) and is available via request to an ORNL U. S. Department of Energy representative. The repository includes the following files for MSTDB:

- Data files in the ASC II .dat format for the full databases.

- Documentation Excel files (data packages) provided for each subsystem which are intended to make information easily traceable to original sources [1-25]. The data packages provide an account of all pure compounds, liquid solutions and solid solutions used in modeling the subsystems with linked references. Modeling parameters from newly performed work are also reported in the data package along with all applicable references.

- An Excel file containing the thermodynamic values used for all pure compounds of the MSTDB along with linked references.

- Readme files in the code.ornl format for each of the major directories of the repository. These files provide details and explanations for the files contained within each major directory.

Complete descriptions of the contents of the solution databases can also be found in the Appendix of this document. The following is a brief description of the database content:

- Liquid solutions are modeled with the Modified Quasi-chemical Model (SUBG ${ }^{1}$ ).

- Solid solutions are modeled by either the Compound Energy Formalism (SUBL ${ }^{1}$ ) or the onelattice polynomial model $\left(\mathrm{QKTO}^{1}\right)$.

- Values for 136 total pure compounds

- Fluoride-based salt systems (nicknamed MSAX):

- Contains the following elements: Be-Ca-Ce-Cs-K-La-Li-Mg-Na-Nd-Ni-Pu-Rb-Th-U-F

- 48 pseudo-binary subsystems (Fig. 1)

- 28 pseudo-ternary subsystems

- 3 higher order systems:

- 23 solid solutions

${ }^{1}$ The four-letter codes reflect the type of solution thermodynamic model that is employed. 


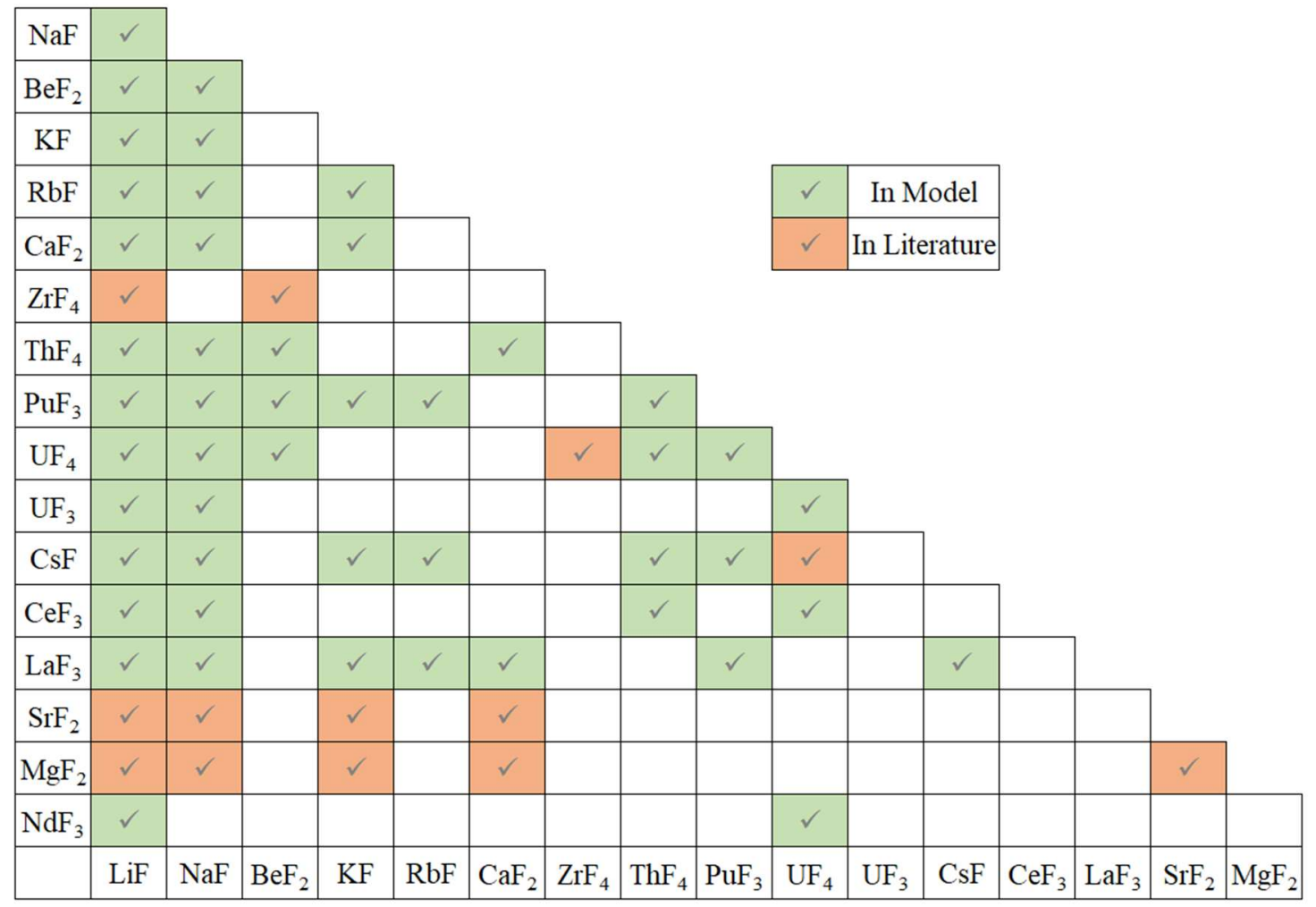

Figure 1 - Fluoride-based pseudo-binary assessment status.

- Chloride-based salt system (nicknamed CLAK):

- Contains the following elements: Cs-K-Li-Mg-Na-Pu-U-Cl

- 12 pseudo-binary subsystems (Fig. 2)

- 1 pseudo-ternary subsystem

- 3 solid solutions

- Models for excess K and Mg in solution

Future updates to the $M S T D B$ will continue to increase the overall capability of the database by incorporating additional published systems as well as newly assessed systems. 


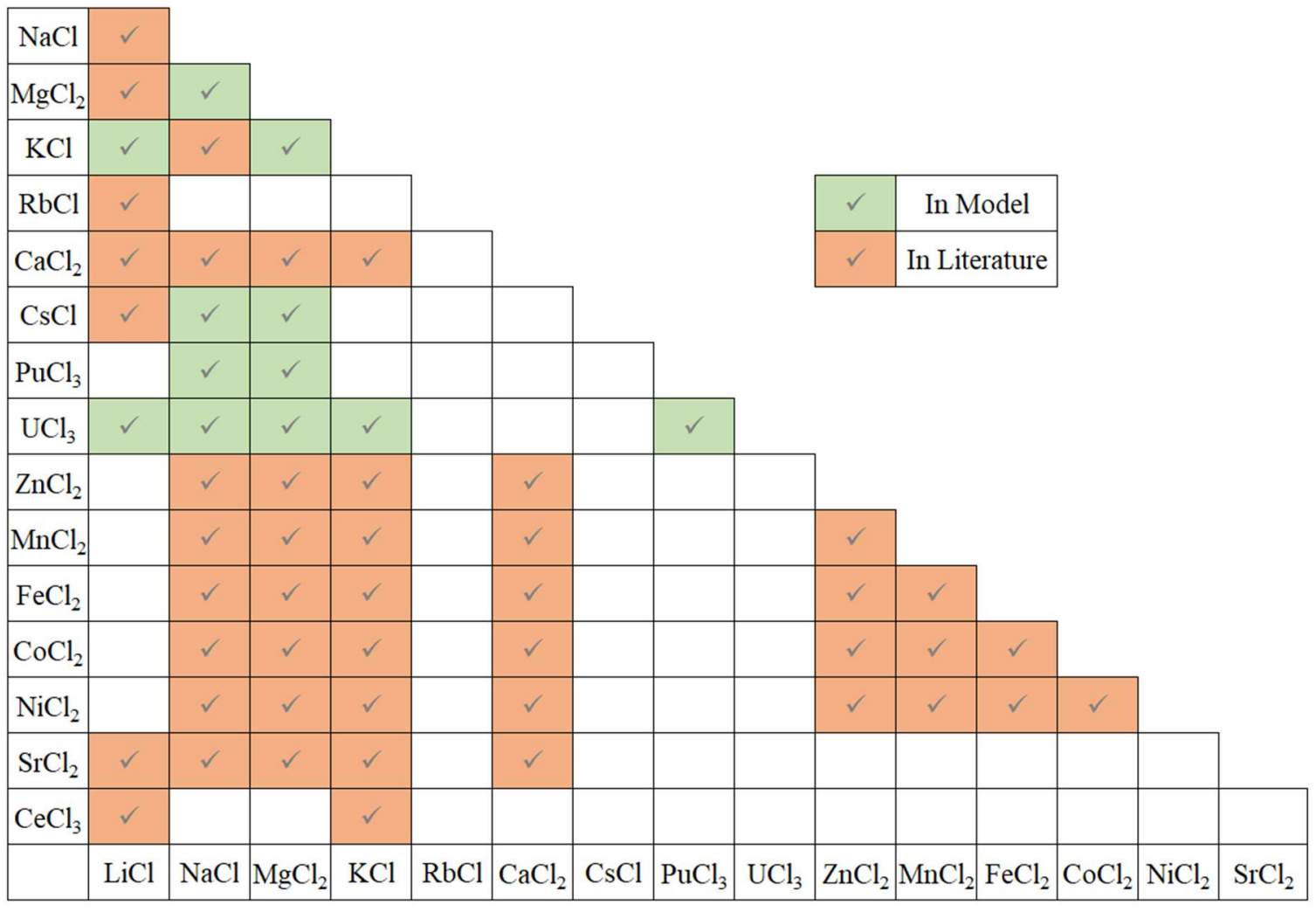

Figure 2 - Chloride-based Pseudo-binary Assessment Status

Note on naming conventions: Versions of the MSTDB databases are identified by four-letter names assigned to files where the first two letters, either MS or CL, designate whether it is fluoride- or chloride-based, respectively. The last two letters are used to increment the version of the database; following the pattern $\mathrm{AA}, \mathrm{AB}, \mathrm{AC}, \ldots, \mathrm{AZ}, \mathrm{BA}, \ldots$, etc. The current datafiles are named MSAX and CLAK, respectively. Similarly, the solid solutions of the $M S T D B$ are assigned four-letter names in where the first two letters are always SS. Each solid solution is assigned an individual pair of last two letters. Currently, aa-bz are reserved for fluoride-based solid solutions, and ca-dz are reserved for chloride-based solid solutions. SSaa-SSay and SSca-SScc are currently in use for the fluoride-based and chloride-based solid solutions, respectively. This may be changed in the future as the number of solid solutions grows.

\section{DEVELOPMENT}

The MSTDB is intended to include both fueled and un-fueled molten salt systems, consequential fission product and transuranic elements, contaminants such as air and moisture, and likely corrosion product elements such as nickel and chromium. Phases include the ideal gas, liquids (e.g., molten salts, noble metals), and solid compounds. Solutions include the fluoride- and chloride-based molten salts as well as a number of solid solutions. The database is provided in the Chemsage ASC II format accessible with the FactSage $^{\circledR}$ commercial thermodynamic software suite and compatible with the open source equilibrium code Thermochimica (i.e., in the .dat format).

The models and values within $M S T D B$ are obtained through combinations of literature-reported information, first principles calculations, and experimental measurements for performing pseudo-binary, pseudo-ternary, and higher order system assessments. A system is said to be assessed when sufficient 
experimental and theoretical data are available to optimize adjustable thermochemical values and parameters for each phase in the system. A system is sufficiently assessed when models and values allow accurate computing of the phase equilibria (e.g. phase diagrams) and attendant values such as heat capacity and vapor pressures.

Maintaining consistency among unary, binary, and other stoichiometric compound thermodynamic values throughout the database is vital as these form the basis on which solution models are developed. As each component in the solution can appear in multiple subsystems, these fundamental values need to be consistent across all solutions. In order to accomplish this, a single set of thermodynamic values must be selected for each compound and used for all solutions. An effort was made to select the most widely accepted thermodynamic values for pure compounds, as any need to change the values in the future could require re-assessment of all affected systems. Due to differences in pure compound values between data sources, development of the current $M S T D B$ required a number of re-assessments of published solution models to allow inclusion in the database.

The following is the list of systems for which published thermodynamic values were re-assessed to allow the database to be consistent across all the components.

$\underline{\text { Re-assessed systems: }}$

- $\quad \mathrm{NaF}-\mathrm{LaF} 3$

- $\mathrm{KF}-\mathrm{RbF}$

- $\mathrm{KF}-\mathrm{CsF}$

- $\mathrm{KF}-\mathrm{CaF} 2$
- $\mathrm{LaF} 3-\mathrm{CaF} 2$

- $\mathrm{ThF} 4-\mathrm{CsF}$

- $\mathrm{LiF}-\mathrm{NaF}$

- $\mathrm{LiF}-\mathrm{CeF} 3$

- NaF-CeF3

- $\mathrm{NaCl}-\mathrm{MgCl} 2$
- $\mathrm{MgCl} 2-\mathrm{CsCl}$

- $\mathrm{MgCl} 2-\mathrm{UCl} 3$

- $\quad$ LiF-ThF4-CaF2

- $\mathrm{LiF}-\mathrm{NaF}-\mathrm{CeF} 3$

- $\mathrm{LiF}-\mathrm{NaF}-\mathrm{ThF} 4$

A conversion issue between FactSage ${ }^{\circledR}$ and Thermochimica was discovered early in MSTDB development in collaboration with Dr. M.H.A Piro at Ontario Tech University. The presence of any two-lattice polynomial (SUBM) solid solutions caused Thermochimica to be unable to import the solution database. As compatibility of the database with Thermochimica is a project goal, it was necessary to re-assess all published models using the SUBM solid solutions so as to utilize one-lattice polynomial (QKTO) models, which could be imported to Thermochimica. Full details of the re-assessed values can be found directly in the systems' data package Excel files available on code.ornl. Below is the list of solid solutions for which this was necessary.

\section{$\underline{\text { SUBM to QKTO converted solid solutions: }}$}

- $\quad \mathrm{SSab}=(\mathrm{Pu}, \mathrm{Th}) \mathrm{Fx}$

- $\quad \mathrm{SSat}=(\mathrm{U}, \mathrm{Pu}) \mathrm{Fx}$

- $\quad \mathrm{SSau}=(\mathrm{U}, \mathrm{Th}) \mathrm{Fx}$

- $\quad \mathrm{SSam}=(\mathrm{Li}, \mathrm{Na}, \mathrm{K}, \mathrm{Rb}, \mathrm{Cs}) \mathrm{F}$

- $\quad \mathrm{SSan}=(\mathrm{Ce}, \mathrm{Th}) \mathrm{F}$

- $\mathrm{SSao}=(\mathrm{Ca}, \mathrm{Th}) \mathrm{F}$

- $\mathrm{SSap} / \mathrm{SSaq}=(\mathrm{Ca}, \mathrm{La}) \mathrm{F}$ 
A number of original assessments have been performed by the Besmann group at University of South Carolina. These utilized published phase equilibria data, thermodynamic values, assessments of proxy systems, and/or reassessments from an original solution model to one preferred for MSTDB, following the CALPHAD method. Full details of the newly assessed systems can be found directly in the system data package Excel files available on code.ornl. Below is the list of newly assessed systems.

Newly assessed systems:

- $\mathrm{NaF}-\mathrm{CeF} 3$

- CeF3-UF4

- $\quad$ LiF-NdF3

- NdF3-UF4

- $\quad$ LiCl-KCl-UCl3

- UF3-UF4

\section{AVAILABILITY}

The MSTDB is hosted on the Oak Ridge National Laboratory code.ornl GitLab repository where the full fluoride- and chloride-based salt solution and compound databases are available in the dat format readable by both FactSage ${ }^{\circledR}$ and Thermochimica. In addition to the full databases, individual dat files are available for all modeled pseudo-binary and pseudo-ternary subsystems. An Excel file containing the thermodynamic values used for all pure compounds in the $M S T D B$ along with linked references is also available in the $\mathrm{mstdb} /$ models/Data_Packages directory of the repository.

To ensure ease of traceability for all database systems, data packages have been generated for each MSTDB subsystem. The data packages are Excel files with multiple sheets which list the compounds, liquid interactions, and solid solutions alongside links to their references. All references used in creating the $M S T D B$ have been assigned an internal reference number, which is consistent across all MSTDB documentation files. Quality assurance testing was performed independently by Oak Ridge National Laboratory where all systems were evaluated against the open literature.

Readme files are included for each of the major directories of the repository that provide up-to-date details and explanation of the contained files. A readme file which contains a full change log for new updates can be found in the main $M S T D B$ directory.

Access to the code.ornl GitLab repository and downloading of the database can be obtained by request to Dr. J. W. McMurray (mcmurrayjw1@ornl.gov).

\section{FUTURE WORK}

The initial release of the $M S T D B$ contains nearly half of publicly available assessed fluoride- and chloridebased salt systems as well as systems newly assessed in the current work. Future updates to the MSTDB are intended to be released as the following tasks are completed:

- The addition of the remaining published systems (Figs. 1 and 2) as well as potentially newly published systems, with re-assessments performed as necessary.

- New system assessments performed at the University of South Carolina, Oak Ridge National Laboratory, and collaborators.

- As needed re-assessments and/or corrections to systems already included in the MSTDB 


\section{ACKNOWLEDGEMENTS}

This works was funded by the US Department of Energy, Office of Nuclear Energy, Nuclear Energy Advanced Modeling and Simulation program. 


\section{REFERENCES}

[1] E. Capelli, O. Benes, R. J. M. Konings, Journal of Nuclear Materials, 449 (1-3) (2014) 111-21.

[2] O. Benes, R. J. M. Konings, CALPHAD, 32 (1) (2008) 121-8.

[3] O. Benes, R. J. M. Konings, Journal of Nuclear Materials, 377 (3) (2008) 449-57.

[4] P. Chartrand, A. D. Pelton, Metallurgical and Materials Transactions a-Physical Metallurgy and Materials Science, 32 (6) (2001) 1385-96.

[5] O. Benes, J. P. M. van der Meer, R. J. M. Konings, Calphad-Computer Coupling of Phase Diagrams and Thermochemistry, 31 (2) (2007) 209-16.

[6] O. Benes, R. J. M. Konings, Journal of Nuclear Materials, 435 (1-3) (2013) 164-71.

[7] J. P. M. van der Meer, R. J. M. Konings, K. Hack, H. A. J. Oonk, Chem. Mater., 18 (2) (2006) 510-7.

[8] E. Capelli, O. Benes, P. E. Raison, M. Beilmann, C. Kunzel, R. J. M. Konings, Journal of Chemical and Engineering Data, 60 (11) (2015) 3166-74.

[9] N. Vozarova, A. L. Smith, J. Y. Colle, P. E. Raison, D. Bouexiere, R. J. M. Konings, O. Benes, Journal of Chemical Thermodynamics, 114 (2017) 71-82.

[10] X. Li, K. Wang, M. Y. Xie, Z. Wu, L. D. Xie, Chemical Research in Chinese Universities, 33 (3) (2017) 454-9.

[11] O. Benes, R. J. M. Konings, Journal of Chemical Thermodynamics, 41 (10) (2009) 1086-95.

[12] E. Capelli, O. Benes, R. J. M. Konings, Journal of Nuclear Materials, 462 (2015) 43-53.

[13] R. Thoma, Phase Diagrams of Nuclear Reactor Materials, Oak Ridge National Laboratory: ORNL2548; 1959.

[14] R. Thoma, Rare Earth Halides, Oak Ridge National Laboratory: ORNL-3804; 1965.

[15] R. E. Thoma, H. Insley, G. D. Brunton, Journal of Inorganic \& Nuclear Chemistry, 36 (5) (1974) 1095-8.

[16] J. A. Ocadiz-Flores, E. Capelli, P. E. Raison, R. J. M. Konings, A. L. Smith, J. Chem. Thermodyn., 121 (2018) 17-26.

[17] M. Beilmann, O. Benes, R. J. M. Konings, T. Fanghanel, Journal of Chemical Thermodynamics, 57 (2013) 22-31.

[18] P. Chartrand, A. D. Pelton, Metallurgical and Materials Transactions a-Physical Metallurgy and Materials Science, 32 (6) (2001) 1361-83.

[19] O. Benes, R. J. M. Konings, Journal of Nuclear Materials, 375 (2) (2008) 202-8.

[20] M. Beilmann, O. Benes, R. J. M. Konings, T. Fanghanel, J. Chem. Thermodyn., 43 (10) (2011) 151524.

[21] O. Benes, M. Beilmann, R. J. M. Konings, Journal of Nuclear Materials, 405 (2) (2010) 186-98.

[22] J. W. McMurray, S. S. Raiman, Solar Energy, 170 (2018) 1039-42.

[23] J. Sangster, A. D. Pelton, Journal of Physical and Chemical Reference Data, 16 (3) (1987) 509-61.

[24] C. Robelin, P. Chartrand, A. D. Pelton, Journal of Chemical Thermodynamics, 36 (8) (2004) 683-99.

[25] S. Ghosh, B. P. Reddy, K. Nagarajan, K. C. H. Kumar, Calphad-Computer Coupling of Phase

Diagrams and Thermochemistry, 45 (2014) 11-26. 
APPENDIX A. LIST OF PHASES IN MSTDB 


\section{APPENDIX A. LIST OF PHASES IN MSTDB}

Full lists of all compounds, pseudo-binary systems, pseudo-ternary systems, and solid solutions included in the initial release of the MSTDB (MSAX and CLAK) are given below. This information can also be found in the code.ornl readme files as well as the MSTDB_Compounds_with_Refs.xlsx file in the $\mathrm{mstdb} /$ models/Data_Packages directory.

\section{Pure Compounds (136):}

\begin{tabular}{|c|c|c|c|}
\hline$(\mathrm{KCl}) 2$ & $\mathrm{~K} 2$ & $\mathrm{MgCl}$ & $\mathrm{PuF}$ \\
\hline $\mathrm{Be}$ & $\mathrm{K} 2 \mathrm{~F} 2$ & $\mathrm{MgCl} 2$ & PuF2 \\
\hline $\mathrm{BeF} 2$ & $\mathrm{~K} 2 \mathrm{MgCl} 4$ & $\mathrm{Na}$ & PuF3 \\
\hline $\mathrm{Ca}$ & $\mathrm{K} 2 \mathrm{MgF} 4$ & $\mathrm{Na} 2 \mathrm{BeF} 4$ & PuF6 \\
\hline $\mathrm{CaF} 2$ & $\mathrm{~K} 2 \mathrm{NiF} 4$ & $\mathrm{Na} 2 \mathrm{MgCl} 4$ & $\mathrm{Rb}$ \\
\hline CaThF6 & K3LaF6 & Na2ThF6 & Rb2LaF5 \\
\hline $\mathrm{Ce}$ & $\mathrm{K} 3 \mathrm{Mg} 2 \mathrm{Cl} 7$ & Na2UF6 & Rb2PuF5 \\
\hline $\mathrm{CeF} 3$ & K3PuF6 & Na3BeTh10F45 & Rb3LaF6 \\
\hline CeTh2F11 & $\mathrm{KCaF} 3$ & Na3Th2F11 & Rb3PuF6 \\
\hline CeThF7 & $\mathrm{KCl}$ & Na3UF7 & $\mathrm{RbF}$ \\
\hline $\mathrm{Cr}$ & $\mathrm{KF}$ & Na4ThF8 & RbLa2F7 \\
\hline $\mathrm{CrCl} 2$ & KLaF4 & Na5U3F17 & RbLaF4 \\
\hline $\mathrm{CrCl} 3$ & $\mathrm{KMgCl} 3$ & Na7Th2F15 & RbPuF4 \\
\hline $\mathrm{CrCl} 4$ & $\mathrm{KMgF} 3$ & Na7Th6F31 & $\mathrm{Sr}$ \\
\hline $\mathrm{CrCl5}$ & $\mathrm{KNiF} 3$ & Na7U6F31 & Th \\
\hline $\mathrm{CrCl6}$ & KPuF4 & $\mathrm{NaBeF} 3$ & Th2F9Li \\
\hline $\mathrm{Cs}$ & $\mathrm{La}$ & $\mathrm{NaCeF} 4$ & Th2PuF11 \\
\hline $\mathrm{Cs} 2 \mathrm{MgCl} 4$ & LaF3 & $\mathrm{NaCl}$ & Th4F17Li \\
\hline Cs2Th3F14 & $\mathrm{Li}$ & $\mathrm{NaF}$ & ThF4 \\
\hline Cs2ThF6 & Li2BeF4 & NaLaF4 & ThF5Li \\
\hline Cs3LaF6 & Li2CaThF8 & $\mathrm{NaMgCl} 3$ & ThF7Li3 \\
\hline $\mathrm{Cs} 3 \mathrm{MgCl} 5$ & Li2NiF4 & NaNiF3 & $\mathrm{U}$ \\
\hline Cs3PuF6 & LiBeF3 & NaPuF4 & U2PuF11 \\
\hline Cs3ThF7 & $\mathrm{LiCl}$ & NaTh2F9 & U4F17Li \\
\hline $\mathrm{CsCaCl3}$ & $\mathrm{LiCs} 2 \mathrm{Cl} 3$ & NaThF5 & U6F31Li7 \\
\hline $\mathrm{CsCl}$ & $\mathrm{LiCsF} 2$ & NaU2F9 & $\mathrm{UCl} 2$ \\
\hline $\mathrm{CsF}$ & $\mathrm{LiF}$ & NaU4F17 & $\mathrm{UCl} 3$ \\
\hline $\mathrm{CsMg} 3 \mathrm{Cl} 7$ & LiNa2Be2F7 & NaUF4 & $\mathrm{UCl5}$ \\
\hline $\mathrm{CsMgCl} 3$ & LiNa5Be3F12 & $\mathrm{Nd}$ & UCl6 \\
\hline CsTh2F9 & LiNaBeF4 & NdF3 & UF3 \\
\hline CsTh3F13 & LiRbF2 & $\mathrm{Ni}$ & UF4 \\
\hline CsTh6F25 & LiU2F9 & NiF2 & UF8Li4 \\
\hline CsThF5 & $\mathrm{Mg}$ & $\mathrm{Pu}$ & $\mathrm{Zn}$ \\
\hline $\mathrm{K}$ & Mg2 & $\mathrm{PuCl} 3$ & $\mathrm{Zr}$ \\
\hline
\end{tabular}




\section{Solid Solutions (26):}

- $\mathrm{SSaa}=(\mathrm{Li}, \mathrm{Na}) 7 \mathrm{Th} 6 \mathrm{~F} 31$

- $\mathrm{SSab}=(\mathrm{Pu}, \mathrm{Th}) \mathrm{Fx}$

- $\mathrm{SSac}=\mathrm{Li}(\mathrm{Th}, \mathrm{U}) 4 \mathrm{~F} 17$

- $\mathrm{SSad}=\mathrm{Li}(\mathrm{Th}, \mathrm{U}) 2 \mathrm{~F} 9$

- $\mathrm{SSae}=\mathrm{Li7}(\mathrm{Th}, \mathrm{U}) 6 \mathrm{~F} 31$

- $\mathrm{SSaf}=\mathrm{Li} 3(\mathrm{Th}, \mathrm{U}) \mathrm{F} 7$

- $\mathrm{SSag}=\mathrm{Na} 2(\mathrm{Th}, \mathrm{U}) \mathrm{F} 6$

- $\mathrm{SSah}=\mathrm{Na} 7(\mathrm{Th}, \mathrm{U}) 6 \mathrm{~F} 31$

- $\mathrm{SSai}=\mathrm{Na}(\mathrm{Th}, \mathrm{U}) 2 \mathrm{~F} 9$

- $\mathrm{SSam}=(\mathrm{Li}, \mathrm{Na}, \mathrm{K}, \mathrm{Rb}, \mathrm{Cs}) \mathrm{F}$

- $\mathrm{SSan}=(\mathrm{Ce}, \mathrm{Th}) \mathrm{Fx}$

- $\mathrm{SSao}=(\mathrm{Ca}, \mathrm{Th}) \mathrm{Fx}$

- $\mathrm{SSap}=(\mathrm{Ca}, \mathrm{La}) \mathrm{Fx}$

(LaF3 destabilized)
- $\mathrm{SSaq}=(\mathrm{Ca}, \mathrm{La}) \mathrm{Fx}$

(CaF2 destabilized)

- $\mathrm{SSar}=(\mathrm{La}, \mathrm{Pu}) \mathrm{Fx}$

- $\mathrm{SSas}=(\mathrm{Na}, \mathrm{Th}) \mathrm{Fx}$

- $\mathrm{SSat}=(\mathrm{U}, \mathrm{Pu}) \mathrm{Fx}$

- $\mathrm{SSau}=(\mathrm{U}, \mathrm{Th}) \mathrm{Fx}$

- $\mathrm{SSav}=\mathrm{Li3ThF7-BeF2-LiBeThF7}$

- $\mathrm{SSaw}=(\mathrm{Li}, \mathrm{Na}) 7 \mathrm{U} 6 \mathrm{~F} 31$

- $\operatorname{SSax}=$ Na7(Th, U)2F15

- SSay $=$ Na3Th2F11-Na5U3F17

- UF34 = UF(3+x)

- $\mathrm{SSca}=(\mathrm{U}, \mathrm{Pu}) \mathrm{Cl} 3$

- $\mathrm{SScb}=(\mathrm{Li}, \mathrm{K}) \mathrm{Cl}$

- $\mathrm{SScc}=(\mathrm{Li}, \mathrm{K}) \mathrm{Cl}$

\section{Fluoride-based System (MSAX):}

MSAX solution database contains Be-Ca-Ce-Cs-K-La-Li-Na-Nd-Pu-Rb-Th-U-F

Pseudo-binary systems (48):

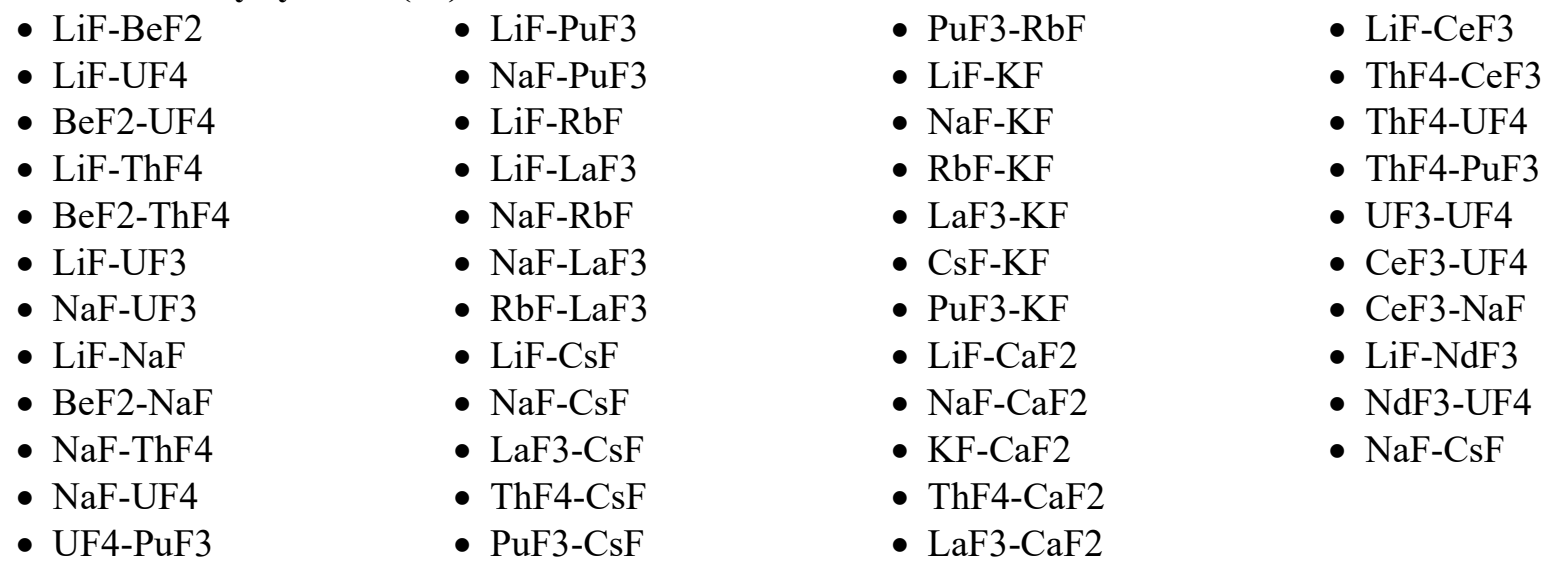

Pseudo-ternary systems (28):

- LiF-BeF2-UF4

- LiF-BeF2-ThF4

- BeF2-UF4-ThF4

- BeF2-NaF-ThF4

- BeF2-NaF-UF4

- LiF-BeF2-NaF

- LiF-NaF-UF4

- NaF-UF4-ThF4

- LiF-ThF4-PuF3
- LiF-UF4-PuF3

- LiF-BeF3-PuF3

- BeF2-NaF-PuF3

- LiF-NaF-LaF3

- LiF-NaF-RbF

- LiF-LaF3-CsF

- LiF-NaF-PuF3

- LiF-PuF3-CsF

- LiF-NaF-KF
- LiF-KF-CsF

- LiF-KF-RbF

- LiF-KF-CaF2

- NaF-KF-CaF2

- LiF-ThF4-CaF2

- LiF-LaF3-CaF2

- NaF-LaF3-CaF2

- LiF-ThF4-CeF3

- LiF-NaF-CeF3 


\section{Chloride-based System Solutions (CLAK):}

CLAK solution database contains Cr-Cs-K-Li-Mg-Na-Pu-U-Cl

Pseudo-binary systems (12):• $\mathrm{NaCl}-\mathrm{MgCl} 2$

- $\mathrm{NaCl}-\mathrm{CsCl}$

- $\mathrm{NaCl}-\mathrm{PuCl} 3$

- $\mathrm{NaCl}-\mathrm{UCl} 3$

- $\mathrm{MgCl} 2-\mathrm{CsCl}$

- $\mathrm{MgCl} 2-\mathrm{PuCl} 3$

- $\mathrm{MgCl} 2-\mathrm{UCl} 3$

- $\mathrm{MgCl} 2-\mathrm{KCl}$

- $\mathrm{PuCl} 3-\mathrm{UCl} 3$

- $\mathrm{LiCl}-\mathrm{KCl}$

- $\mathrm{LiCl}-\mathrm{UCl} 3$

- $\mathrm{KCl}-\mathrm{UCl} 3$

- $\mathrm{K}-\mathrm{KCl}$

- $\mathrm{Mg}-\mathrm{MgCl} 2$

Pseudo-ternary systems (1 Total):

- KCl-LiCl-UCl3 